\title{
Phase I Study with SV-BR-1 Breast Cancer Cell Line Vaccine and GM- CSF: Clinical Experience in 14 Patients
}

\author{
Charles L. Wiseman ${ }^{*}, 1$ and Alex Kharazi ${ }^{2}$

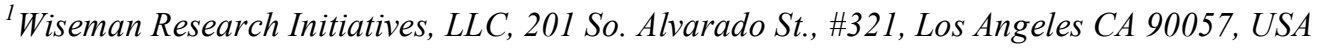 \\ ${ }^{2}$ Stemedica Inc., (Previously Immunotherapy Laboratory St. Vincent Medical Center) 5375 Mira Sorento Pl. \#100; San \\ Diego, CA 92121, USA
}

\begin{abstract}
We evaluated the safety and feasibility of breast cancer vaccine therapy using a new cell line, SV-BR-1, in conjunction with repeated injections of GM-CSF, as a prototype for a subsequent genetically engineered vaccine. Also addressed with this preliminary trial were monitoring effects on quality of life, screening for potential immune responses, and evaluating any clinical effects on tumor progression and patient survival. Fourteen patients with metastatic breast cancer were treated with SV-BR-1 tumor cells. The cell line strongly overexpresses HER2/neu, and has an unusual variety of cytogenetic abnormalities. Irradiated whole-cell suspensions (median dose $14 \times 10^{6}$ viable cells) were inoculated via intradermal injection or intralymphatic cannulation, the former usually including an equal amount of irradiated autologous peripheral blood lymphocytes (PBL). Vaccine was initially given at 2-week intervals x3, then monthly. Low-dose cyclophosphamide $300 \mathrm{mg} / \mathrm{m}^{2}$ was given $48-72 \mathrm{hrs}$ prior to vaccine, and GM-CSF (125 mcg) was given subcutaneously immediately prior and for 8 days subsequently. The Kaplan-Meier mean survival for all 14 patients was 17.2 months (CI 5.8-28.5 months) and was 21.1 months (95\% CI 5.0-37.2 months) for nine patients treated with the tumor cell/PBL admixture, although there were no clinical regressions. SV-BR-1 as a whole-cell vaccine appears feasible and without obvious major toxicity. The overall survival compares favorably with current Phase I studies. Based on these observations, we have initiated a clinical trial using the SV-BR1 cell line transfected to release GM-CSF in situ with four patients to date. One case responded with clear evidence of tumor regressions in multiple sites and the median survival of 35.0 months is three times longer than usual expectations for salvage programs.
\end{abstract}

Keywords: Immunotherapy, breast cancer, vaccine therapy, breast cancer cell line.

\section{INTRODUCTION}

Breast cancer is a public health problem of enormous importance, occurring in about 1 of 8 women and accounting for the death of 40,000 persons in the U.S. in 2007. The median overall survival (OS) for metastatic breast cancer is about 24 months, and many new drugs are now available, but few patients enjoy complete remission and fewer are longterm survivors $[1,2]$. After first-line therapy, median OS is generally cited to be about 6-12 months [3]. Clearly, the development of new approaches is very much needed.

In hopes of influencing host responses to breast cancer, there has been a growing number of investigators involved with development of therapeutic tumor vaccines [4-10]. Consistent with this concept, although certainly not conclusive, a previous study, in part influencing the clinical trial here described, used a whole-cell vaccine in combination with chemotherapy and documented a $30 \% 10$ year survival in a small cohort of inflammatory breast cancer patients [9]. One Stage IV breast cancer patient (noninflammatory), with bone and pulmonary metastases, was also treated under this protocol, experiencing unmaintained complete remission for 30 years [Wiseman, unpublished data].

*Address correspondence to this author at the 201 So. Alvarado St., Suite 321, Los Angeles, CA 90057, USA; Tel: (213) 483-8464; Fax: (213) 4838307; E-mail: cwiseman@wisemanresearch.com
While breast cancer is not generally considered an "immunogenic" tumor, whose antigens commonly elicit clinically useful antibody and cellular responses, there is evidence for the existence of potentially useful tumorassociated antigens. Early work in the 1970's demonstrated autologous humoral [11] and cellular immune responses [12] although the antigen(s) eliciting these responses is unknown. More recent work identified a number of tumor-associated antigens, such as CEA, CA 27.29, p53, MAGE 3, MUC 1, and sTn [6]. Also, the HER2/neu receptor is a well-studied and clinically important breast cancer antigen. HER2/neu is the target of a clinically effective monoclonal antibody and also the basis of a systematic vaccine trial $[8,13]$, notable not only for generating immune responses against the target antigen but also generating responses against other breast cancer associated antigens by "epitope spreading" [15]. Since our new cell line, SV-BR-1, shows very strong overexpression of $\mathrm{HER} 2 / \mathrm{neu}$, we felt encouraged to implement a clinical vaccine trial using this new cell line in the allogeneic setting. The objective of this preliminary safety study was to facilitate further investigations with this cell line using gene transfection methodology [16].

We describe here a whole-cell vaccine study in 14 patients. The cell line, SV-BR-1, was established from a chest wall lesion of a 39-year-old woman with metastatic breast cancer. The study employed immunization with an irradiated, whole-cell suspension, which had been incubated previously with interferon-gamma to upregulate cell-surface 
antigenicity just prior to cryopreservation [17,18]. Additionally, we employed low-dose cyclophosphamide, 4872 hours prior to vaccine treatment for down-regulation of regulatory T-cells [19], a rationale that has been described as improving both immune response and clinical prognosis in a randomized trial [20]. The program also provided granulocyte-macrophage colony stimulating factor (GMCSF) immediately before vaccine and for 8 days following for the purpose of up-regulating antigen presenting cell activity [21-24]. Some patients were treated with vaccine having an admixture of autologous irradiated peripheral blood lymphocytes in the tumor cell inoculum, to provide in situ additional dendritic cells that might possibly respond to the tumor cell/GM-CSF regimen.

\section{MATERIALS AND METHODS}

\section{Patients}

The 14 patients started treatment between May 1999 and August 2003 and are described in Table 1. The mean age was 54.8 years $(\mathrm{SD}=10.5$; median $=53.1$ years $)$, with a minimum of 39 and maximum of 74 years. Eleven of 14 were ER positive, six of 13 were PR positive and six of 12 patients were HER2/neu positive. The number of prior chemotherapy regimens ranged from one to five, with a median of three. Metastases to lung, bone, liver and nodes were common, and almost all patients had two or more metastatic sites. One patient, \#11, was clinically inevaluable for response because of her metastases having previously responded to chemotherapy and radiation. The study was carried out with FDA approval and oversight by the St. Vincent Medical Center IRB. All subjects signed informed consent documents. The studies, BB-IND 2749 and BB-IND 10312 were registered on CancerTrials.gov.

\section{MATERIALS}

Vaccine. The cell line SV-BR-1 is characterized as ER negative, PR negative, and Her2/neu very strong. Quality control tests on the master cell bank required sterility (bacterial, mycoplasma, and adventitious viruses), and absence of evidence of endotoxin; Hep B and C, EBV, CMV, Parvovirus, HIV, HTLV and T pallidum.

The cell line has been passaged more than 40 times, and all patients in this study were treated with lots \#1-4. For each lot preparation, the cell line was propagated in T-75 and T150 flat-bottom flasks in RPMI-1640 culture medium (Irvine Scientific), supplemented with 10\% fetal bovine serum (Irvine Scientific), $2 \mathrm{mM}$ glutamine (BioWhittaker), and $40 \mathrm{mM}$ tobramycin (complete medium) until reaching $80-100 \%$ confluency. Prior to harvesting, the cells were incubated with interferon-gamma (Genentech) $100 \mathrm{U} / \mathrm{ml}$ in antibiotic-free RPMI-1640 complete culture medium for 48 hrs. The cells were harvested using $0.05 \%$ trypsin -0.53 $\mathrm{mM}$ EDTA solution (Gibco), and cell count and viability were determined. The cells were resuspended in freezing medium, aliquoted to $15 \times 10^{6}$ viable cells $/ \mathrm{ml}$, and frozen in liquid nitrogen. Aliquots of each lot were again submitted for general sterility testing, mycoplasma testing and endotoxin testing. No lots failed any of these quality control assays.

For clinical application, interferon-treated tumor cells were removed from liquid nitrogen, thawed rapidly at $37^{\circ} \mathrm{C}$, and resuspended in $20 \mathrm{ml}$ HBSS. The cells were then centrifuged and resuspended in lactated Ringer's solution. After gamma-irradiation $(20,000 \quad \mathrm{cGy}, \quad$ GammaCell irradiator), the cell count and trypan-blue viability were determined. The cells were washed and resuspended in lactated Ringer's solution to provide at least 5 to $15 \times 10^{6}$ viable cells in 2-2.5 ml. All steps were performed aseptically. The selection of 20,000 cGy as the appropriate

Table 1. Patient Characteristics

\begin{tabular}{|c|c|c|c|c|c|c|c|c|}
\hline Pt. \# & $\begin{array}{l}\text { Age } \\
\text { (yrs) }\end{array}$ & ER & PR & Her2/neu & $\begin{array}{l}\text { \# Previous } \\
\text { Chemo }\end{array}$ & $\begin{array}{c}\text { Years from } \\
\text { dx to 1st met }\end{array}$ & $\begin{array}{l}\text { Yrs from dx to } \\
\text { 1st Vaccine }\end{array}$ & Metastases \\
\hline 1 & 44.0 & + & + & + & 3 & 2.0 & 5.2 & Chest, brain \\
\hline 2 & 55.9 & - & - & - & 2 & 2.0 & 5.7 & $\begin{array}{l}\text { Liver, adrenal, lung, } \\
\text { endobronchial }\end{array}$ \\
\hline 3 & 74.3 & + & - & - & n.a. & 4.0 & 5.8 & Lung \\
\hline 5 & 39.6 & + & - & + & 3 & 1.0 & 1.8 & Lung, chest wall, nodes \\
\hline 6 & 63.2 & + & + & - & 5 & 0.0 & 2.0 & Liver, lung, bone \\
\hline 7 & 59.4 & + & - & + & 1 & 8.0 & 9.2 & Lung, bone, nodes \\
\hline 8 & 43.7 & - & + & $-/+$ & n.a. & 2.0 & 6.8 & Bone, brain \\
\hline 12 & 48.4 & + & - & + & 4 & 0.5 & 2.9 & Bone, liver, brain \\
\hline 13 & 47.6 & + & + & + & 3 & n.a. & 3.2 & Bone, skin, nodules \\
\hline 14 & 65.1 & + & + & - & 2 & 9.0 & 11.2 & Effusion, soft tissue, nodes, bone \\
\hline
\end{tabular}


dose of irradiation is consistent with current practice for allogeneic vaccines. Also, BrdU/propidium incorporation flow cytometry studies [28] indicated complete cell-cycle arrest at this dose. Irradiated cells would not re-establish tissue culture growth and there was nothing clinically notable to suggest persistence or growth of residual tumor cells at any of the inoculation sites of vaccine or skin tests in 54 procedures.

The SF36 Health Survey [26]. A well-validated measure of health-related quality of life, the SF36 measures eight health concepts: Physical Functioning (PF), Role Functioning - Physical (RF), Bodily Pain (BP), General Health (GH), Vitality (V), Social Functioning (SF), Role Functioning - Emotional (RE), Mental Health (MH) Scores range from 0 to 100 , representing the percentage of the total possible score achieved. The higher the score, the better is the perceived health.

\section{Procedures}

Pre-vaccine low-dose cyclophosphamide was given as a single dose by intravenous infusion 48-72 hours before vaccine. Premedication with antiemetics was permitted, provided no corticosteroids were included. Three vaccine inoculations were administered initially at 2-week intervals. Beginning week 9, patients changed schedule to receive inoculations at monthly intervals, for 3 months, provided there was no evidence of undue toxicity and no new or enlarging sites of tumor. Nine monthly inoculations (to a total of 12 overall) were provided if patient was stable or improving, as characterized by clinical and periodic imaging evaluations. After each group of 3 vaccines, and 2 weeks after the last vaccine, patients were reevaluated clinically, and also with laboratory and imaging studies. They also were asked to complete the quality of life questionnaire.

We used several inoculation strategies in this pilot evaluation trial of feasibility and safety. After reconstituting, vaccine was administered to 12 patients by intradermal (ID) injection, of which 9 patients also received an equal number $\left(10^{-20} \times 10^{6}\right)$ of irradiated cryopreserved autologous peripheral blood lymphocytes (PBL) obtained previously by leukapheresis and admixed in the inoculum. The combination of PBL with vaccine was based on the notion that the presence of GM-CSF modulated antigen presenting cells admixed with vaccine cells would enhance T-cell recognition and activation. The cells were injected in two divided doses, into the right and left thigh after a test dose of 1 million irradiated tumor cells into the forearm to assess immediate and delayed hypersensitivity.

Two patients received vaccine by injection into a dorsal pedal lymphatic channel, and one of the intradermal patients also later received intralymphatic (IL) injection evaluating feasibility in comparison to previous intralymphatic vaccine studies by our group. GMCSF was injected subcutaneously about $10 \mathrm{~cm}$ distal to the chosen site of intradermal vaccine inoculation, immediately prior to vaccine and repeated daily for 8 days subsequently after each inoculation, to varying sites in the ipsilateral thigh.

Anti-SV-BR-1 ELISA Methodology: To screen for antibodies against tumor cell surface antigens, including the overexpressed HER2/neu, we used a cell-based ELISA assay with live tumor cells in solid phase. SV-BR-1 breast carcinoma cells were seeded into $75 \mathrm{~T}$ tissue-culture flasks in RPMI-1640 medium containing 10\% FCS and allowed to grow to near-confluence. Two days before harvesting, cells were incubated in medium containing $100 \mathrm{U} / \mathrm{ml}$ IFN-gamma. Cells were removed from plastic using a $0.05 \%$ trypsin, washed, resuspended in growth medium with $10 \%$ DMSO and frozen in liquid nitrogen.

On the day of experiment, cells were thawed and their viability was checked by $0.25 \%$ trypan blue. Cells were distributed $5 \times 10^{5}$ viable cells per well into the wells of 96well U-bottom plates.

Patients' sera were collected and stored at $-70^{\circ} \mathrm{C}$. On the day of experiment, pre- and post-vaccine serum samples were thawed and diluted in PBS containing $20 \%$ fetal calf serum (FCS). FCS was added to PBS in order to absorb antibodies specific to bovine proteins. After the absorption step $\left(1 \mathrm{hr}\right.$ at $\left.4^{\circ} \mathrm{C}\right)$, the samples were serially diluted $1: 100$ to 1:1,600 in 2-fold steps and mixed with target cells. Plates were incubated at $4^{\circ} \mathrm{C}$ for $2 \mathrm{hrs}$ with periodic low-speed vortexing.

After 3 washes in $20 \%$ FCS, cells were mixed with peroxidase-conjugated antibody specific to human $\operatorname{IgG}$ $(\mathrm{H}+\mathrm{L})$ and incubated for $1 \mathrm{hr}$ at $4{ }^{\circ} \mathrm{C}$.

The last three washes were done in serum-free PBS. To avoid false positive results caused by peroxidase molecules attached to plastic, cells were transferred into a new plate. Activity of cell-bound peroxidase was measured using a tetramethylbenzidine substrate. Absorbance of blue product was measured at $650 \mathrm{~nm}$ using an $E^{\max }$ plate reader (Molecular Devices, Palo Alto, CA).

Antibody levels were expressed as the last serum dilution (end-titer) giving an OD value greater than the cut-off level. Cut-off level was set as background OD value multiplied by two. Assay background caused by non-specific binding of peroxidase-conjugated secondary antibody was defined as the average OD of wells that were incubated without patients' serum.

Fetal Calf Serum Antibody Methodology: Anti-FCS antibodies were detected by ELISA according to a modified protocol described previously by Dols and colleagues [5]. Fetal calf serum (FCS) was diluted 1:10 in $0.1 \mathrm{M} \mathrm{Na}_{2} \mathrm{HPO}_{4}$ $\mathrm{pH}$ 8.5. The 96-well enhanced protein binding plates (Immulon ${ }^{\circledR} 4$ HBX, Dynex) were filled with $10 \%$ FCS at 100 $\mu 1 /$ well and incubated for 2 days at $+4^{\circ} \mathrm{C}$. Serum samples were diluted 1:100 in PBS supplemented with $25 \mathrm{mM}$ HEPES pH 7.4, $0.05 \%$ Tween ${ }^{\mathbb{B}} 20$ and $25 \mathrm{mg} / \mathrm{ml}$ human serum albumin. Serum samples were then titrated in 2-fold steps: $1: 100$ to $1: 800$ for pre-vaccine and $1: 100$ to $1: 12,800$ for post-vaccine samples. The Immulon ${ }^{\mathbb{B}}$ plates were thoroughly washed with $300 \mu \mathrm{l} /$ well of $0.05 \%$ Tween ${ }^{\circledR} 20$ in PBS for 5 times of 5 min each using an orbital shaker and filled with titrated serum samples at $100 \mu \mathrm{l} /$ well. Plates were sealed and incubated for $16 \mathrm{hrs}$ at $+4^{\circ} \mathrm{C}$. After overnight incubation, plates were washed 5 times and peroxidaseconjugated goat antibody against human immunoglobulins (Caltag) was added for $1 \mathrm{hr}$. Plates were washed 5 times with $\mathrm{PBS} / \mathrm{Tw}^{\mathrm{B}}{ }^{\circledR} 20$. For the final wash step, PBS/Tween ${ }^{\circledR} 20$ was replaced with $0.1 \mathrm{M}$ acetate buffer $\mathrm{pH}$ 5.5. Plates were developed with tetramethylbenzidine (TMB) peroxidase substrate buffer for 15 min. Optical density of blue TMB 
product was measured using $\mathrm{E}^{\max }$ plate reader (Molecular Devices).

All 28 pre- and post-vaccine samples collected from 14 patients were analyzed simultaneously. Anti-FCS antibody level was expressed as the last serum dilution giving an OD value greater than the cut-off level. Cut-off level was set as background OD multiplied by 3. Assay background was defined as the average OD of the wells that were not incubated with patients' serum.

\section{RESULTS}

We administered 54 tumor cell vaccines to 14 patients with metastatic breast cancer. The median dose was $14 \times 10^{6}$ cells, ranging from $9-41 \times 10^{6}$, with median viability of $94 \%$ (ranging from $73-97 \%$ ).

\section{Clinical Observations}

While most patients showed progressive disease after the initial induction phase of three vaccines, 5 patients showed stabilization and continued to receive vaccine at monthly intervals. No patients developed significant clinical regression, although many patients reported improved sense of well-being as measured in various categories. Further details regarding quality of life are described below.

Overall Kaplan-Meier mean survival was 17.2 months, 95\% CI 5.8-28.5 months; median 9.5 months, with a range from 1.2 to $85+$ months.

The survival curve for just the nine patients who received tumor cell/PBL inocula is shown in Fig. (2), in which the mean survival is 21.1 months, (95\% CI 5.0-37.2 months); median survival is 14.3 months. Five of 9 patients treated with SV-BR-1/PBL survived at least 12 months and three survived 24 months or more. One patient (\#11) remains alive at 85 months since first inoculation.

Table 2 shows the type of vaccine each patient received, the number of treatments (median 3, range 2-7) and survival times. One patient (Number 11) remains alive at 85 months. Survival post-vaccine did not correlate with previous length of time to first metastases or with the interval between diagnosis and initiation of vaccine therapy. There did seem to be a trend towards a negative correlation $(\mathrm{r}=-.55, \mathrm{p}=.07)$ between number of previous chemotherapy regimens and survival -- the greater the number of previous treatments, the shorter the survival following vaccine.

\section{Toxicity}

Toxicity was mild and consisted principally of erythema and pruritus at injection sites (Table 3). One patient developed transient atrial fibrillation and one patient, after 3 inoculations, declined further treatment for psychological reasons.

\section{Immunologic Activity}

The results of antibody screening and delayed-type hypersensitivity (DTH) testing are provided in Table 4. DTH was assessed immediately prior to the first and subsequent vaccines using $10^{6}$ irradiated tumor cells injected intradermally into the forearm. Inoculation of vaccine was to be aborted in the event of acute hypersensitivity, defined as respiratory distress, pruritus, uriticaria or enlargement of the skin test by $2 \mathrm{x}$, as other vaccine studies in our program had identified [25]. However no such incidents occurred. Positive DTH was defined as $5 \mathrm{~mm}$ or more induration

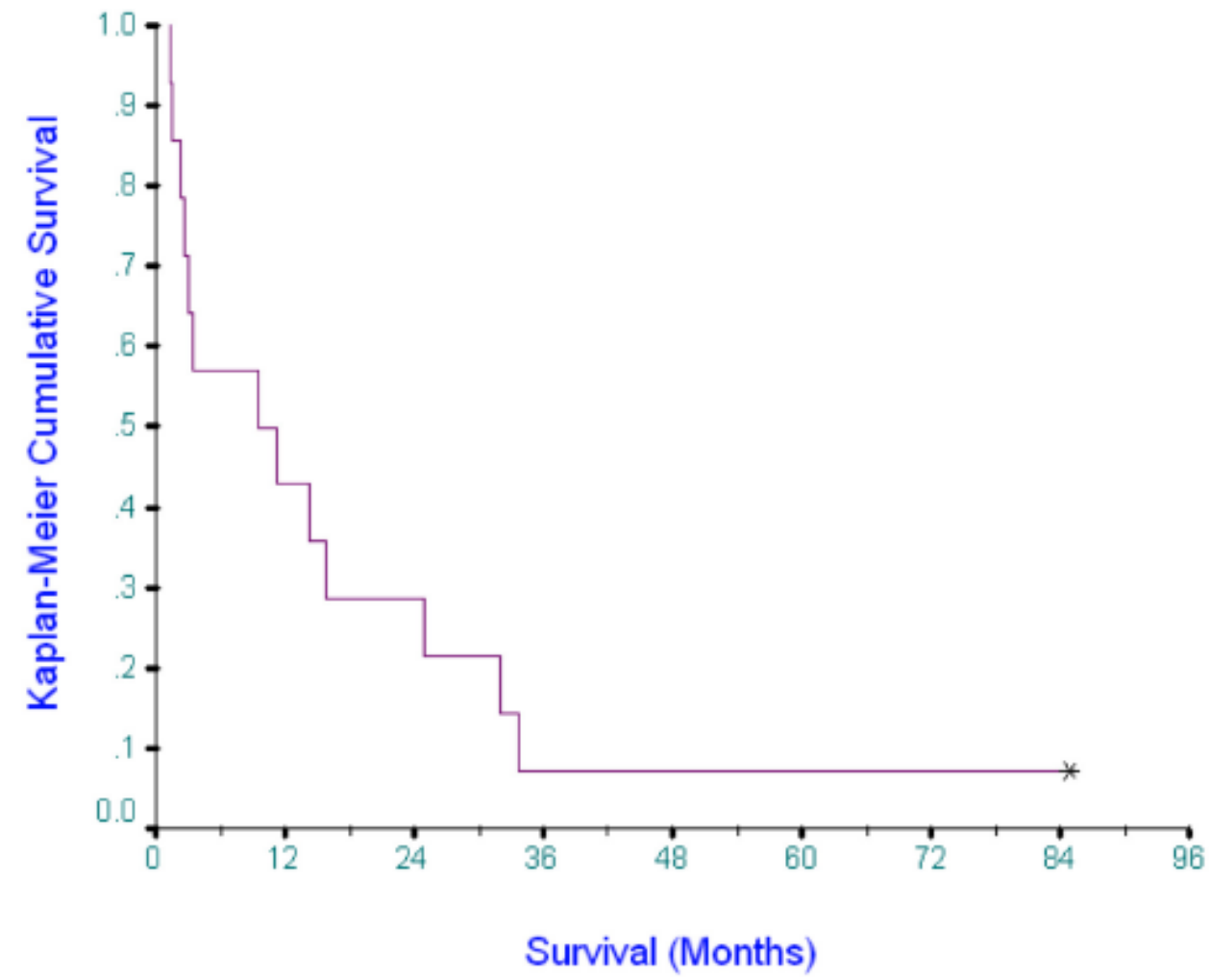

Fig. (1). Survival of all 14 breast cancer patients treated with tumor cell vaccine using cell line SV-BR-1. Mean Kaplan-Meier survival = 17.2 months (median $=9.5$ months). Asterisk shows censored data point for patient still alive. 


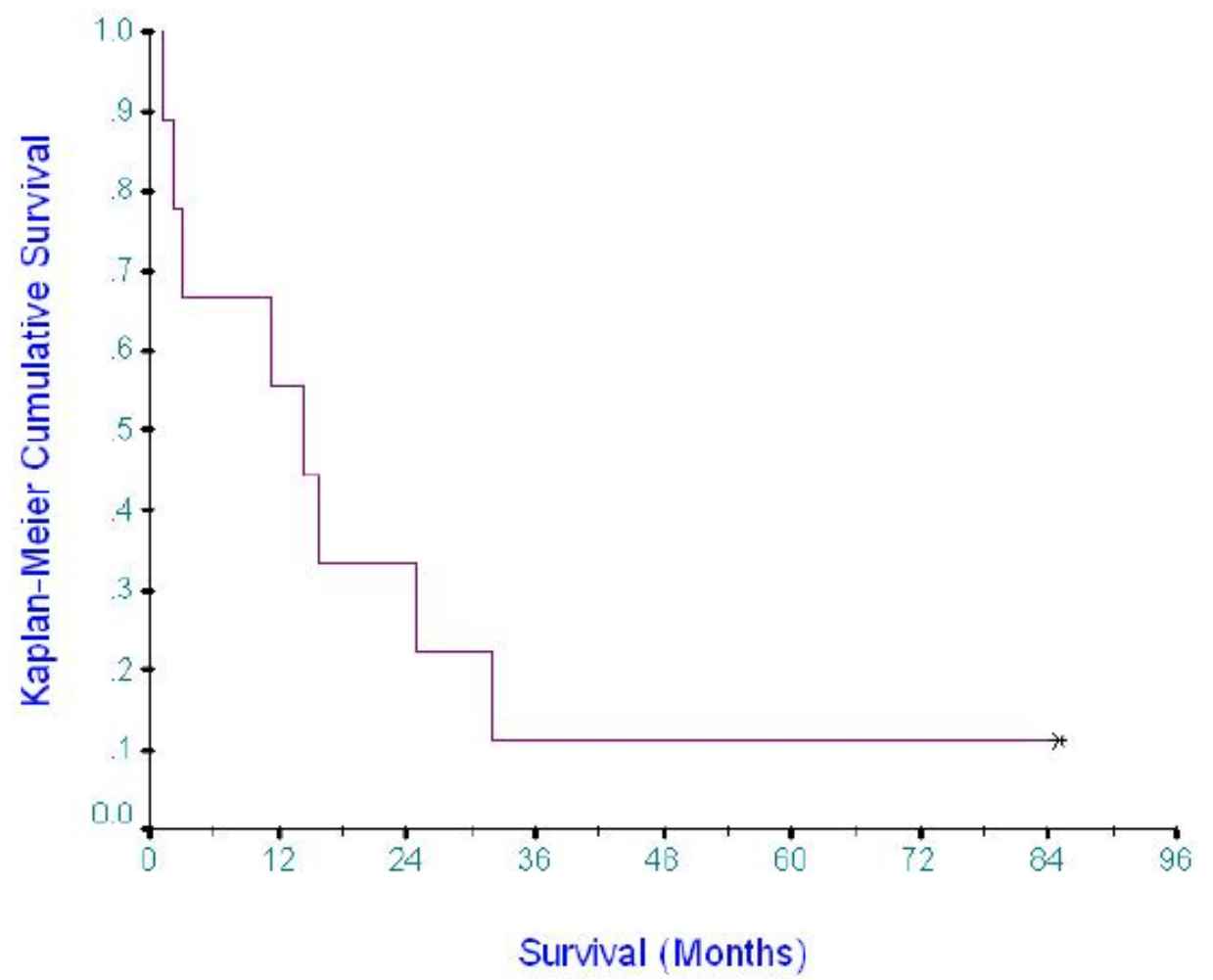

Fig. (2). Survival of 9 breast cancer patients treated with tumor cell vaccine using cell line SV-BR-1 and peripheral blood lymphocytes. Mean Kaplan-Meier survival $=21.1$ months $($ median $=14.3$ months $)$. Asterisk shows censored data point for the patient still alive.

occurring 48 to 72 hours after injection, and was identified in 7 cases at initiation of treatment. Post-treatment skin test results were heterogeneous. Two patients changed from a negative pretest to a positive posttest, one changed from positive to negative, two remained positive, one remained negative and the remainder had unclear findings or no posttest available.

Table 2. Type of Vaccine, Number of Injections and Survival

\begin{tabular}{|c|c|c|c|}
\hline Pt\# & Type Vaccine & Injections & Survival (Months) \\
\hline \hline 1 & IL & 4 & 9.4 \\
\hline 2 & IL & 2 & 2.7 \\
\hline 3 & ID/IL & 7 & 33.4 \\
\hline 4 & ID & 3 & 1.5 \\
\hline 5 & ID & 3 & 3.3 \\
\hline 6 & PBL/ID & 2 & 1.2 \\
\hline 7 & PBL/ID & 3 & 15.6 \\
\hline 8 & PBL/ID & 4 & 31.8 \\
\hline 9 & PBL/ID & 3 & 24.7 \\
\hline 10 & PBL/ID & 3 & 3 \\
\hline 11 & PBL/ID & 3 & 85.0 (alive) \\
\hline 12 & PBL/ID & 4 & 2.2 \\
\hline 13 & PBL/ID & 3 & 11.2 \\
\hline 14 & PBL/ID & 5 & 14.3 \\
\hline
\end{tabular}

Type of vaccine inoculation: IL intralymphatic, ID intradermal; PBL/ID intradermal with peripheral blood lymphocyte/tumor cell-line admixture.
Table 3. Toxicity

\begin{tabular}{|l|c|c|c|}
\hline \multicolumn{1}{|c|}{ SWOG Category } & Grades 1-2 & Grades 3 & Grade 4 \\
\hline \hline Fever & 3 & & \\
\hline Nausea & 4 & & \\
\hline Vomiting & 1 & & \\
\hline Diarrhea & 2 & & \\
\hline Constipation & 2 & & \\
\hline Cellulitis/Lymphangitis & 2 & & \\
\hline Local skin reaction & 1 & & \\
\hline Pruritus & 1 & & \\
\hline Anemia & 1 & $1 *$ & \\
\hline Leukopenia & 1 & & \\
\hline Thrombocytopenia & 2 & & \\
\hline Arrhythmia & 1 & & \\
\hline Increased pain & & & \\
\hline GI Bleed & & & \\
\hline Candida colonization & 1 & & \\
\hline Pedal edema & 1 & & \\
\hline Myalgia & & & \\
\hline Exacerbation of preexisting condition. & & \\
\hline
\end{tabular}

The initial ELISA screening for humoral responses to whole-cell preparations of SV-BR-1 found 5 of 14 patients 
developed identifiable antibody responses. Using pretreatment and post-vaccine sera saved after 2-9 inoculations, the serology assay commenced with a 1:100 dilution. The change in titer was never more than $2-4 x$, and a change occurred in only 5 patients. Additional serologic studies identified increased anti-FCS titers of 2-16 fold in 10 of the 14 patients $(71 \%)$. Preexistent anti-FCS antibody was identified in five subjects, but rarely exceeded a 1:100 titer. None with preexistent antibody lost this reactivity. The median anti-FCS titer pretreatment was 0; post-treatment it was 1:400. One patient with very high preexistent titers, $1: 1600$, demonstrated yet an additional $4 \mathrm{x}$ increase in titer after 3 vaccine treatments. Correlation analysis with survival did not suggest a relation between prognosis and the ability to mount an immune response, albeit a non-specific one. These findings indicate at least some preservation of immune response capability in very advanced breast cancer patients.

Table 4. Immunologic Activity, Including Changes in ELISA Screening for Humoral Responses to SV-BR-1 and Antibody to Fetal Calf Serum (FCS) and DelayedType Hypersensitivity (DTH) Skin Test Results Prior to First Vaccine and After Vaccine

\begin{tabular}{|c|c|c|c|c|c|}
\hline \multirow{2}{*}{ Pt. \# } & \multirow{2}{*}{$\begin{array}{c}\text { Whole-Cell } \\
\text { ELISA }\end{array}$} & \multicolumn{2}{|c|}{ Anti-FCS } & \multicolumn{2}{c|}{ DTH Skin Test } \\
\cline { 3 - 6 } & & Pre & Post & Pre & Post \\
\hline \hline 1 & No change & 0 & $1: 200(2 \mathrm{x})$ & + & n.a. \\
\hline 2 & No change & 0 & $1: 1600(16 \mathrm{x})$ & + & n.a. \\
\hline 3 & $2 \mathrm{x}$ & 0 & $0(0)$ & - & n.a. \\
\hline 4 & No change & 0 & $1: 100(<2 \mathrm{x})$ & + & ++ \\
\hline 5 & No change & 0 & $1: 400(4 \mathrm{x})$ & - & - \\
\hline 6 & $2 \mathrm{x}$ & 0 & $0(0)$ & + & n.a. \\
\hline 7 & No change & $1: 1600$ & $1: 6400(4 \mathrm{x})$ & + & + \\
\hline 8 & $4 \mathrm{x}$ & $1: 100$ & $1: 800(8 \mathrm{x})$ & + & n.a. \\
\hline 9 & No change & $1: 100$ & $1: 400(4 \mathrm{x})$ & n.a. & n.a. \\
\hline 10 & No change & 0 & $1: 200(2 \mathrm{x})$ & - & + \\
\hline 11 & No change & $1: 100$ & $1: 400(4 \mathrm{x})$ & - & n.a. \\
\hline 12 & $4 \mathrm{x}$ & $1: 100$ & $1: 1600(16 \mathrm{x})$ & + & - \\
\hline 13 & No change & 0 & $1: 100(<2 \mathrm{x})$ & - & n.a. \\
\hline 14 & $2 \mathrm{x}$ & 0 & $1: 400(4 \mathrm{x})$ & - & + \\
\hline
\end{tabular}

\section{Quality of Life}

The SF-36 health Survey was presented at initiation of treatment and repeated approximately one month after first vaccine treatment. Data were available for 12 of the 14 patients. This instrument demonstrated how severely these patients were impaired by their illness. Table $\mathbf{5}$ shows initial scores on the SF-36. Shown for comparison are the normative data for the general adult U.S. population. These patients were well below the general population (poorer perceived health) on most of the scales, with the exceptions of Role-Functioning - Emotional and Mental Health. These latter scales deal with the extent to which emotional problems interfere with work or other daily activities and general mental health, including depression, anxiety, behavioral-emotional control, and general positive affect. The patients particularly had physical functioning limitations, pain, and poor general health.

Table 5. Initial Scores on the Eight SF-36 Health Survey Scales for 12 Patients with Breast Cancer, Also Showing Normative Data for the General U.S. Adult Population

\begin{tabular}{|l|c|c|c|c|}
\hline \multicolumn{1}{|c|}{ Scale } & Mean & (S.D) & Median & Norm \\
\hline \hline Physical Functioning & 52.5 & $(27.5)$ & 50.0 & 84 \\
\hline Role Functioning - Physical & 43.8 & $(47.8)$ & 25.0 & 81 \\
\hline Bodily Pain & 50.5 & $(19.0)$ & 46.5 & 75 \\
\hline General Health & 47.1 & $(19.6)$ & 46.0 & 72 \\
\hline Vitality & 45.0 & $(24.7)$ & 50.0 & 61 \\
\hline Social Functioning & 63.5 & $(25.9)$ & 62.8 & 83 \\
\hline Role Functioning - Emotional & 75.0 & $(45.2)$ & 100.0 & 81 \\
\hline Mental Health & 68.3 & $(14.1)$ & 74.0 & 75 \\
\hline
\end{tabular}

Follow-up scores were obtained after 2 to 6.1 weeks (mean $=4.3$ weeks; $\mathrm{SD}=1.2$ ). Mean changes for each of the subtests were relatively small, but variability was large. Only one of the eight subtests showed a statistically significant change; Social Functioning worsened an average of 12.5 points, a statistically significant decline in function $(\mathrm{p} \leq$ .027). However, when individual subjects were categorized as improved, unchanged, or worse based on changing more than 10 points in either direction, six of the eight subtests had patients who showed improvement over the one-month period. Fig. (3) shows the percentage of patients who improved. Bodily Pain and Mental Health had the largest percentages of patients showing improvement $(58 \%$ and $41.7 \%$, respectively). Only two patients rated Mental Health as poorer at follow-up, and pain ratings did not remain unchanged for anyone, getting either better or worse.

\section{DISCUSSION}

Breast cancer immunotherapy studies have employed a diverse roster of vaccine preparations; whole cell preparations, cell lysates, and more purified, defined antigens have been applied in clinical trials $[2,4,5]$. This report builds on our previous experience with whole-cell vaccines, involving inflammatory breast cancer, which, after long-term followup, also suggested prolonged survival and acceptable toxicity [9]. The application of this new cell line, SV-BR-1, seems to have acceptable safety, and this investigation found a median survival at least as good as many recent Phase I studies. While the suggestion of improved survival may, of course, be associated with selection bias, it is clear that the cohort treated involved very advanced disease and very extensive previous treatment. Notably, there was no statistical correlation between survival after vaccine and the interval between initial diagnosis and enrollment on study. Also, the subjective claim of improved well-being, reduced pain, and increased vitality is noted.

The efforts to screen for relevant immune responses identified development of anti-FCS antibody to whole cell vaccine, and did not substantiate engendering specific 


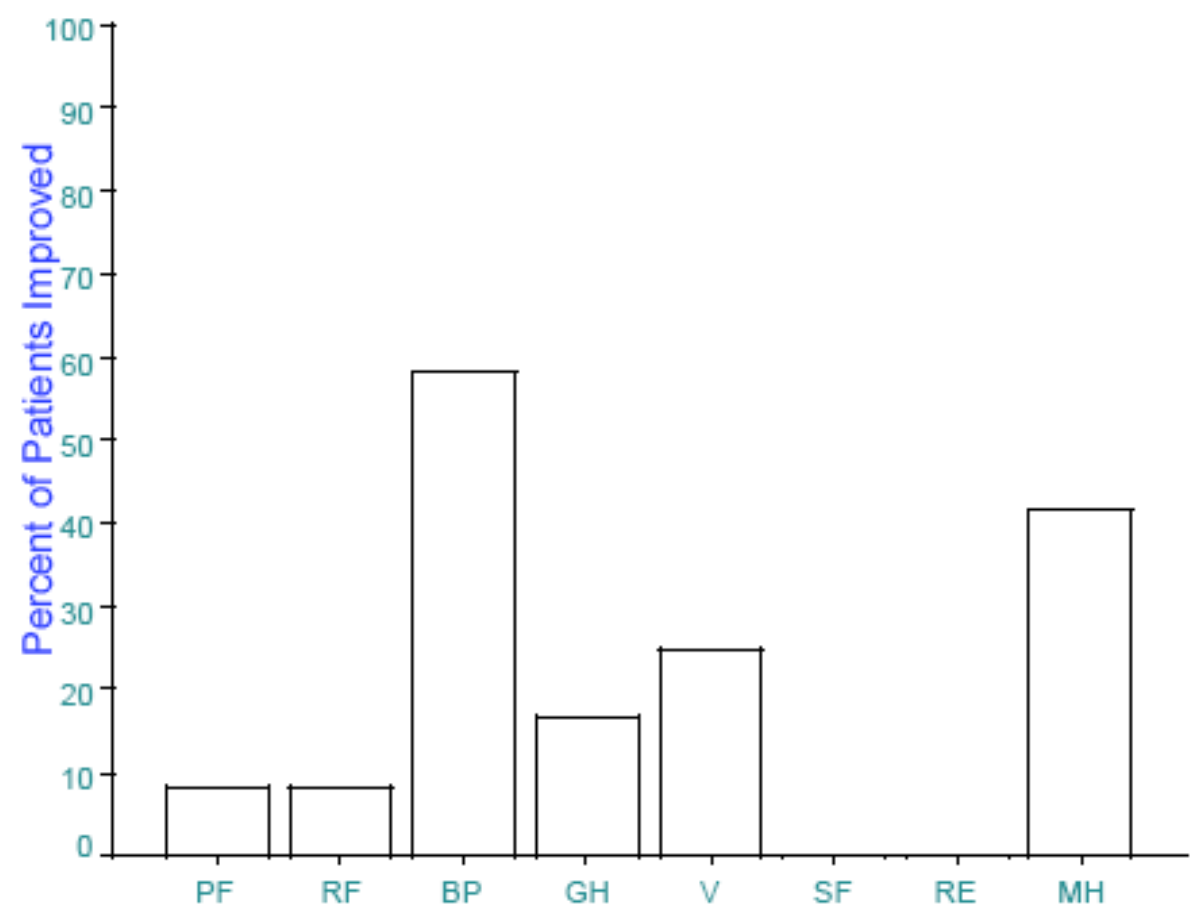

\section{SF-36 Subtest}

Fig. (3). Percentage of patients who showed improvement of 10 points or more in perceived health on each SF-36 subtest. ( $\mathrm{n}=12$ ). $\mathrm{PF}=$ Physical Functioning, RF=Role Functioning - Physical, BP=Bodily Pain, GH=General Health, V=Vitality, SF=Social Functioning, $\mathrm{RE}=$ Role Functioning - Emotional, $\mathrm{MH}=$ Mental Health.

antibody to vaccine (or tumor). The first author's early research described the existence of autologous and allogeneic humoral responses of breast cancer patients to breast cancer cell lines but not to other cell lines cultured in FCS [11]. Antibody studies suffer from the availability of multiple different assay procedures, some targeting whole cells, some targeting cell extracts, and most having somewhat different mechanisms and definitions of positive identification of the sought-after antibody. Anti-fetal calf serum antibody has been reported by Dols, et al. although the assay was performed on cell lysates, not whole cells [5]. The development of "unwanted" immune responses is discussed by Wadhwa et al., who point out the possibility of overlooking more specific low-affinity antibody [27]. None of our current series of patients manifested immediate hypersensitivity to skin tests or food allergy as we had seen occasionally in an analysis of 148 patients treated in our earlier studies [25].

Skin test results indicated the presence of preexisting immune reactivity, and were inconclusive as to effect of the therapy. Determining whether the skin test results were indicative of anti-FCS activity, anti-HLA reaction, etc. will require further evaluations.

Although there was a range of dosages administered, there was no mechanism established in this pilot study to evaluate dose-response effect. Some studies indicate a requirement for 50-100 × $10^{6}$ for biological responses [10]. The study by Dols et al. demonstrated upregulation of immune responses using gene-transfected allogeneic whole- cell breast cancer vaccine inoculations of $10^{7}-10^{8}$ cells per inoculum, more closely resembling this report [5].

This cohort was initiated to evaluate safety and toxicity as a prelude to evaluating a GM-CSF gene-transfected vaccine, BB-IND 10312 (www.wisemanoncology.com), and a case report has since been published from this new study, showing regression of advanced disease in multiple sites, including cerebellar metastases [15]. Several recent reviews of breast cancer vaccines have been published [4, 6, 7], but the application of tumor vaccines in advanced disease is generally avoided. Our unique observation of widespread regressions of metastatic disease, clearly identifiable after only 3 vaccine inoculations ( 7 weeks), is a finding quite at variance from the conventional notion that immune responses require many months to develop and may not prevent initial growth of new lesions [29]. Furthermore, most authorities expect salvage chemotherapy median survivals of 6-12 months [3 ]. The median survival of the first cohort of 14 patients compares favorably. While possibly explainable by selection bias, it is very remarkable that the four patients in the newer ongoing study had survival times of $7,34,36$, and 40 months. The lack of toxicity, the feasibility of implementing this program in a non-academic community hospital and the responses and long survival of the subsequent patients all give strong encouragement for continued work with this program.

\section{CONCLUSION}

SV-BR-1 as a whole-cell vaccine appears feasible and without obvious major toxicity. The overall survival compares favorably with other Phase I-II clinical studies. 
Based on these observations, we have initiated a clinical trial using the SV-BR1 cell line transfected to release GM-CSF in $s i t u$, and preliminary results are encouraging.

\section{CONFLICT OF INTEREST}

The work was originally conducted as a physiciansponsored IND, supported by the sources mentioned in the acknowledgments. The current program is supported by the Wiseman Research Initiatives, LLC, and the Wiseman Cancer Research Foundation, a tax-exempt 501c3 public charity. Dr. Wiseman has rights to the cell lines because of an approved US patent. Dr. Wiseman is a member of the advisory board of IrisBiotech, Inc. and the Community Advisory Board of Genentech USA, Inc.

\section{ACKNOWLEDGMENTS}

This work was funded by the Ahmanson Foundation, the St Vincent Medical Center and the Daughters of Charity Foundation, the Zwick family, and others. The authors appreciate the critical comments of Dr. Cary Presant who reviewed earlier versions of this work. Angie Cuevas provided invaluable laboratory assistance, Karen I. Berliner, $\mathrm{Ph}$.D. performed data analysis and helped in editing the manuscript, Diana Zagalskaya diligently helped with data management and Michael McMonigle, M.D. headed the radiological team involved with lymphangiogram procedures.

We also wish to thank all of the referring physicians who entrusted the care of their patients to us for this investigational study.

\section{REFERENCES}

[1] Briest S, Stearns V. Chemotherapeutic strategies for advanced breast cancer. Oncology 2007; 21(11): 1325-35.

[2] Wilcken N, Dear R. Chemotherapy in metastatic breast cancer : a summary of all randomized trial 2000-2007. Eur J Cancer 2008; 44(15): 2218-25.

[3] Tacca O, LeHeurteur M, Durando X et al. Metastatic breast cancer: overall survival related to successive chemotherapies. What do we gain after the third line? Cancer Investig 2009; 27: 81-5.

[4] Ko BK, Kawano K, Murray JL, et al. Clinical studies of vaccines targeting breast cancer. Clin Cancer Res 2003; 9: 3222-34.

[5] Dols $\mathrm{A}$, Meijer $\mathrm{S}, \mathrm{Hu} \mathrm{H}$, et al. Identification of tumor-specific antibodies in patients with breast cancer vaccinated with gene-modified allogeneic tumor cells. J Immunother 2003; 26: 163-70.

[6] Smith SE, Stopeck AT. Vaccine therapy for breast and ovarian cancers. In: Morse MA, Clay TM, Lyerly HK, Eds. Handbook of cancer vaccines. Totowa (NJ): Humana Press Inc. 2004; pp. 465-89.

[7] Curigliano G, Spitaleri G, Dettori M, et al. Vaccine immunotherapy in breast cancer treatment: promising, but still early. Expert Rev Anticancer Ther 2007; 7(9): 1225-41.

[8] Holmes JP, Gates JD, Benavides LC, et al. Optimal dose and schedule of an HER-2/neu (E75) peptide vaccine to prevent breast cancer recurrence. Cancer 2008; 113: 1666-75.

[9] Wiseman CL. Inflammatory breast cancer: 10 year follow-up of a trial of surgery, chemotherapy, and allogeneic tumor cell/BCG immunotherapy. Cancer Investig 1995; 13: 267-71.

[10] Emens LA, Armstrong D, Biedrzycki B, et al. A phase I vaccine safety and chemotherapy dose-finding trial of an allogeneic GM-CSFsecreting breast cancer vaccine given in a specifically timed sequence with immunomodulatory doses of cyclophosphamide and doxorubicin. Hum Gene Ther 2004; 15: 313-37.

[11] Wiseman C, Cailleau R, Olive M, et al. Autologous and homologous immunofluorescent antibody to established breast cancer cell lines. In Vitro 1980; 16: 629-33.

[12] Hortobagyi GN, Gutterman JU, Blumenschein G, et al. Immunotherapy and chemoimmunotherapy for human breast cancer. In: Immunotherapy of Human Cancer. NewYork: Raven Press 1978; pp. 321-45.

[13] Disis ML, Gooley TA, Rinn K, et al. Generation of T-cell immunity to the HER-2/neu protein after active immunization with HER-2/neu peptide-based vaccines. J Clin Oncol 2002; 20: 2624-32.

[14] Disis ML, Grabstein KH, Lleath PR, et al. Generation of immunity to the Her2/neu oncogenic protein in patients with breast and ovarian cancer using a peptide-based vaccine. Clin Cancer Res 1999; 5: 128997.

[15] Disis ML, Goodell V, Schiffman K, et al. Humoral epitope-spreading following immunization with a HER-2/neu peptide based vaccine in cancer patients. J Clin Immunol 2004; 24: 571-8.

[16] Wiseman CL, Kharazi A. Objective clinical regression of metastatic breast cancer in disparate sites after use of whole-cell vaccine genetically modified to release sargramostim. Breast J 2006; 12(5): 475-80.

[17] Maio M, Gulwani B, Langer JA, et al. Modulation by interferons of HLA antigen, high-molecular-weight melanoma associated antigen, and intercellular adhesion molecule 1 expression by cultured melanoma cells with different metastatic potential. Cancer Res 1989; 49: 2980-7.

[18] Boyer CM, Dawson DV, Neal SE, et al. Differential induction by interferons of major histocompatibility complex-encoded and nonmajor histocompatibility complex-encoded antigens in human breast and ovarian carcinoma cell lines. Cancer Res 1989; 49: 2928-34.

[19] Berd D, Maguire Jr H, Mastrangelo M. Induction of cell-mediated immunity to autologous melanoma cells and regression of metastases after treatment with a melanoma cell vaccine preceded by cyclophosphamide. Cancer Res 1986; 46: 2572-7.

[20] MacLean GD, Miles DW, Rubens RD, et al. Enhancing the effect of THERATOPE STn-KLH cancer vaccine in patients with metastatic breast cancer by pretreatment with low-dose intravenous cyclophosphamide. J Immunother Emphasis Tumor Immunol 1996; 19: 309-16.

[21] Borrello I, Pardoll D. GM-CSF-based cellular vaccines: a review of the clinical experience. Cytokine Growth Factor Rev 2002; 13: 185-93.

[22] Della Bella S, Nicola S, Riva A, et al. Functional repertoire of dendritic cells generated in granulocyte macrophage-colony stimulating factor and interferon-alpha. J Leukocyte Biol 2004; 75: 106-16.

[23] Markowics S, Engleman EG. Granulocyte-macrophage colonystimulating factor promotes differentiation and survival of human periphereal blood dendritic cells in vitro. J Clin Invest 1990; 85: 955-61.

[24] Paquette R, Hsu N, Kiertscher SM, et al. Interferon-alpha and granulocyte-macrophage colony-stimulating factor differentiate peripheral blood monocytes into potent antigen-presenting cells. J Leukocyte Biol 1998; 64: 358-67.

[25] Wiseman CL, Kharazi AI, McMonigle M, et al. Survey of acute hypersensitivity and autoimmune responses in 148 patients treated with intralymphatic whole-cell vaccine, low-dose cyclophosphamide, and GMCSF. Abstracts of the 56th Annual Research Symposium "Cancer Immunity: Challenges for the Next Decade"; Houston, Tx: M.D. Anderson 2003; vol. I-41: pp. 127-128.

[26] Medical Outcomes Trust. How to score the SF-36 Health Survey. Boston: The Health Institute. New England Medical Center 1994.

[27] Wadhwa M, Bird C, Dilger P, et al. Strategies for detection, measurement and characterization of unwanted antibodies induced by therapeutic biologicals. J Immunol Meth 2003; 278: 1-17.

[28] Anon Methods in Cell Biology BD Biosciences, BD PharMingen 2000

[29] Weber J. Previously treated metastatic melanoma treated with antiCTLA-4: delayed kinetics of response. Oncology 2008; 22(11): 30(Supplement).

This is an open access article licensed under the terms of the Creative Commons Attribution Non-Commercial License (http://creativecommons.org/licenses/by-nc/ 3.0/) which permits unrestricted, non-commercial use, distribution and reproduction in any medium, provided the work is properly cited. 